\title{
Robot-assisted laparoscopic partial nephrectomy: Early single Canadian institution experience
}

\author{
Guillaume Ploussard, MD, PhD; Richard Haddad, MD, FRCPC; Evan Kovac, MD; Patrick Richard, MD, FRCSC; \\ Maurice Anidjar, MD, FRCSC; Franck Bladou, MD, FRCSC
}

Department of Urology, Jewish General Hospital, McGill University, Montreal, QC

Cite as: Can Urol Assoc J 2013;7(9-10):348-54. htrp://dx.doi.org/10.5489/cuai.753 Published online October 7, 2013.

\section{Abstract}

Background: Although robot-assisted partial nephrectomy (RALPN) has been increasingly adopted, open procedures continue to be the reference nephron-sparing technique. We describe our initial surgical outcomes of RALPN in our single institution robotic program. Methods: Between January 2011 and February 2013, 65 consecutive patients underwent a RALPN by 2 surgeons. Preoperative characteristics, including the R.E.N.A.L. nephrometry score, perioperative parameters, and postoperative course, including renal function, were assessed from a retrospective database. The mean follow-up was 12 months.

Results: The mean age was 60.2 years and the mean tumour size was $3.9 \mathrm{~cm}$. According to the R.E.N.A.L. nephrometry score, the tumours were classified moderately and highly complex tumours in $51 \%$ and $18.5 \%$ of cases, respectively. Median warm ischemia time (WIT) was 21 minutes. Factors associated with WIT were R.E.N.A.L. nephrometry score, tumour size, complication rates and surgeon experience. No conversion or grade 4 to 5 complications were reported. The mean hospital stay was 3 days. The overall complication rate was $24.6 \%$ (re-admission rate $7.7 \%$ ), and decreased to $12 \%$ after 20 cases. After these initial 20 cases, a trifecta rate (no margins, preserved renal function, no complications) of $64.3 \%$ was achieved in moderately and highly complex tumours. The mean change in estimated glomerular filtration rate was $6.7 \mathrm{~mL} /$ min without severe postoperative renal failure.

Interpretation: RALPN is a safe and feasible procedure with low specific morbidity, even in moderately or highly complex renal masses. The WIT depends on tumour characteristics, mainly determined by the R.E.N.A.L. nephrometry score and is improved by surgeon experience. Longer follow-up is needed to assess the oncologic mid-term safety of the procedure.

\section{Introduction}

During the last decades, the increased radiologic detection of renal masses has led to a significant stage migration towards smaller and less aggressive renal masses. ${ }^{1}$ Concomitantly, partial nephrectomy has been increasingly recommended over radical nephrectomy for $\mathrm{T} 1$ renal cancers. ${ }^{2}$ Advantages of nephron-sparing procedures included improved renal functional outcomes without compromising the oncologic safety. ${ }^{3}$ Partial nephrectomy using open techniques provides excellent long-term oncologic control. ${ }^{4}$ Reported outcomes of laparoscopic partial nephrectomy have suggested comparable oncologic and functional outcomes. ${ }^{5}$

Although robotic technology has been increasingly adopted in onco-urologic surgery, long-term oncologic outcomes are not available. ${ }^{6,7}$ Robotic assistance overcomes the technical challenges of laparoscopic partial nephrectomy and facilitates the realization of complex procedures. Thus, RALPN has been associated with more favourable warm ischemia time (WIT) or lower risk of conversion to radical nephrectomy as compared to the pure laparoscopic procedure..$^{8-11}$ This outcome has led to an increased use of robotic technology for partial nephrectomy indications at the expense of open procedures over the last few years. ${ }^{12}$ An expanding range of indications for RALPN towards more complex renal masses has also been highlighted in experienced teams with good surgical outcomes. ${ }^{13,14}$ Most of the series have been published by American or European teams. In this report, we describe the first Canadian single-institution experience reporting the surgical outcomes after RALPN.

\section{Methods}

\section{Robotic program and study population}

Our robotic program began in 2007. We performed mainly robotic-assisted radical prostatectomies until 2011. In January 2011, the RALPN program began and we started to use it as the first-line modality. Two robotic surgeons were experienced in robot-assisted radical prostatectomy before 
performing RALPN. Only 1 surgeon had a previous experience in pure laparoscopic partial nephrectomy (52 cases).

All consecutive patients were included in this analysis. We reviewed medical charts, including patient characteristics, tumour factors, intraoperative features and postoperative outcomes.

\section{Preoperative planning, patient positioning, port placement}

The R.E.N.A.L. nephrometry score was calculated for each patient using findings from computed tomography or magnetic resonance imaging scans. ${ }^{15}$

The 4-arm daVinci Surgical System (Intuitive Surgical Inc., Sunnyvale, CA) was available, but generally used in a 3-arm configuration.

Each patient was positioned in the full lateral flank. A $1-\mathrm{cm}$ incision was performed on the rectus line at the level of the ombilical line. A transperioneal approach was used. Two 8-mm robotic trocars were inserted under visual control: one in the hypochondriac region $2-\mathrm{cm}$ lower to the costal rib and one in the iliac region. One 12-mm trocar was inserted in the hypogastric region. A third robotic trocar may be added in the hypogastric region if needed. Similar port placements were used for right and left sides. For the right-sided procedure, one $5-\mathrm{mm}$ trocar in the epigastric region was added for liver retraction.

\section{Surgical steps}

The procedure was performed according to standard rules of partial nephrectomy, including bowel mobilization, hilum dissection, tumour exposure, clamping, tumour excision, renorraphy and unclamping. The dissection of the hilum was performed with circumferential liberation of vein and artery, and both were put on a silk loop. Once tumour exposure was achieved, intraoperative ultrasonography was used to define tumour location and extent before hilar clamping and tumour excision. Margins of resection of the renal capsule were scored with cautery to delineate the boundaries. Hilar arterial clamping was then performed with laparoscopic bulldog clamp. The tumour was excised using curved robotic scissors with adequate macroscopic margins of normal parenchyma. The tumour was then placed in the endocatch bag with the peritumoral fat. For renal reconstruction, a 25-cm PDS 3-0 suture was secured by one LapraTy and one 10-mm Hem-o-lok clip was used for clip-sliding the suture. A first deep suture was performed to achieve hemostasis and repair any entry into the collecting system. A second superficial suture was performed to ensure capsular reconstruction. Once the clamp was removed, a bovine-derived gelatin matrix (Floseal, Baxter Inc., Hayward, CA) was systematically placed on the reconstructed capsule. Once hemostasis was checked, the perirenal fat was sutured by a PDS 3-0 suture. A Jackson Pratt drain was placed in the retroperitoneal space. The robotic platform was un-docked and the bag was removed from the abdominal cavity.

\section{Postoperative course}

Intravenous fluids, prophylaxis for deep vein thrombosis and analgesics were postoperatively prescribed. Clear fluids were allowed in the evening. The drain and the Foley catheter were removed the day after the surgery. Ambulation was encouraged. Blood tests were monitored on day 0 and day 1 . The patient was then discharged from the department on postoperative days 2 or 3 .

\section{Statistical analysis}

Collected data included patient characteristics, preoperative tumour characteristics and R.E.N.A.L. nephrometry score on imaging, intraoperative parameters, pathologic features and postoperative outcomes. Factors influencing WIT were assessed in univariate and multivariate (logistic regression) models. Intraoperative parameters, such as WIT, estimated blood loss and operative time, were compared according to surgeon experience (1-20 vs. $>20$ cases). Renal function was assessed by creatinin level and estimated glomerular filtration rate (eGFR) was calculated by the Chronic Kidney Disease Epidemiology Collaboration (CKD-EPI) formula. ${ }^{16}$ Mild, moderate and severe renal failure were defined by an eGFR 60-90, 30-60 and $<30 \mathrm{~mL} / \mathrm{min}$ per $1.73 \mathrm{~m}^{2}$, respectively. The trifecta rate, as defined by Hung and colleagues, was assessed. ${ }^{17}$ Continuous variables were compared using the Mann-Whitney's test. Qualitative variables were compared by Fisher's or chi-square tests as appropriate. Statistical analyses were performed using SPSS software (SPSS Inc, Chicago, IL). The limit of statistical significance was defined as $p<0.05$.

\section{Results}

\section{Demographics and tumour characteristics}

Demographics are listed in Table 1. The mean age was 60.2 years. Patients were predominantly male $(58.5 \%)$. The mean body mass index (BMI) was $29.2 \mathrm{~kg} / \mathrm{m}^{2}$. The American Society of Anesthesiologists (ASA) score was $>2$ in $29.2 \%$ of patients. The preoperative mild and moderate renal failure rate was $38.3 \%$ and $7.7 \%$, respectively.

The characterization of tumours on preoperative imaging is shown in Table 2. Bifocal tumours were removed in 4 patients. The mean R.E.N.A.L. nephrometry score was 7.6 and $40.7 \%$ of tumours were greater than $4 \mathrm{~cm}$. Overall, $50.8 \%$ and $18.5 \%$ of tumours were classified as moderately and highly complex renal masses, respectively. 


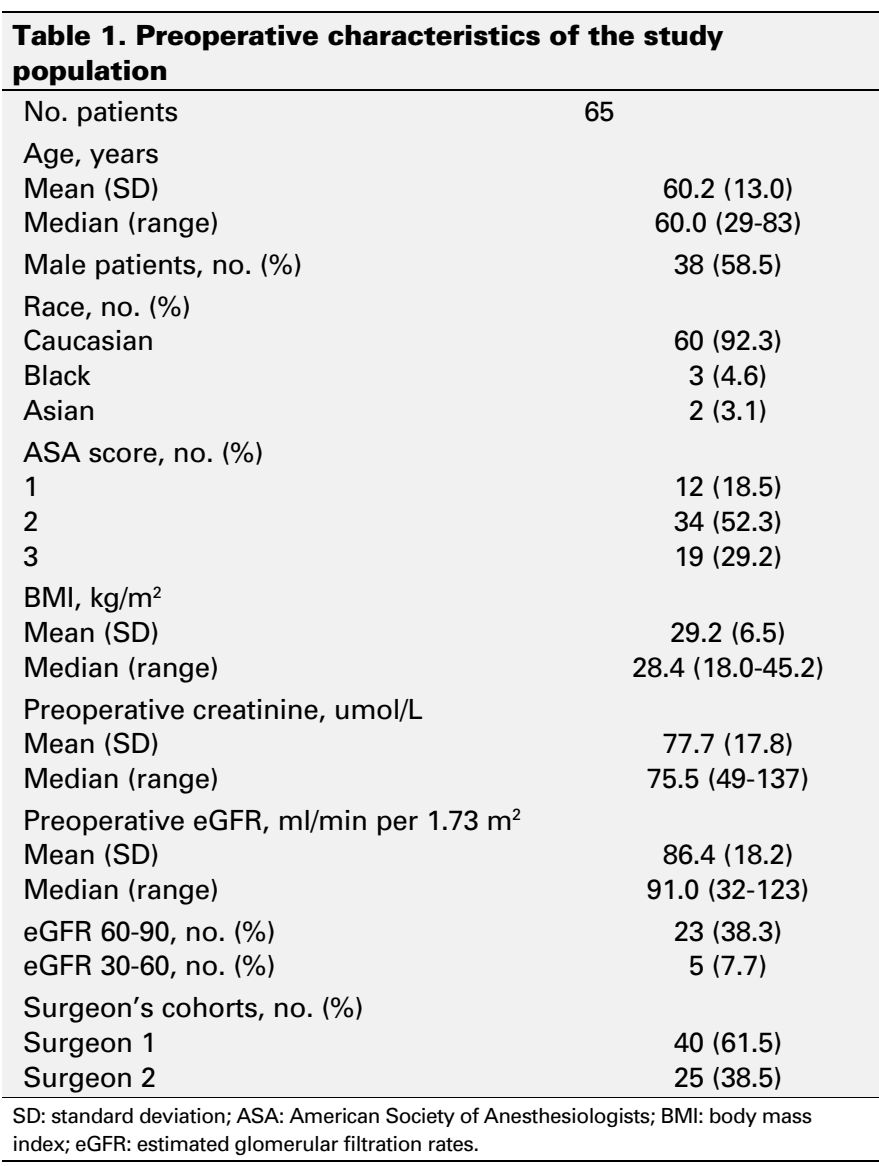

\section{Perioperative outcomes (Table 3 and 4)}

Perioperative outcomes were tallied (Table 3, Table 4). The median WIT was 21 minutes. The median estimated blood loss and operative time were $150 \mathrm{cc}$ and 183 minutes, respectively. The R.E.N.A.L. nephrometry score negatively influenced the estimated blood loss $(p=0.029)$ and operative time ( $p=0.032)$. The complication rate was $24.6 \%$, with a lower rate of Clavien grade 3 complications (12.3\%). All complications were successful resolved by ureteral stents ( 2 urine leakages) and angio-embolization (4 pseudo-aneurysms). No intra-operative conversion was reported. There was no grade 4-5 complication. Re-admission was needed in 6 patients due to bleeding requiring interventional radiology $(n=1)$, urine leakage $(n=2)$, pseudo-aneurysm $(n=3)$.

Postoperative renal function is tallied in Table 4. The mean percent of eGFR preservation was $92 \%$ after surgery. The median increase in creatinin level was $5.5 \mathrm{umol} / \mathrm{L}$ and the median decrease in eGFR was $4.5 \mathrm{~mL} / \mathrm{min}$ per $1.73 \mathrm{~m}^{2}$. No severe renal failure cases were reported. The mean follow-up was 12 months (range: 1-26) and no local and metastatic recurrences were reported.

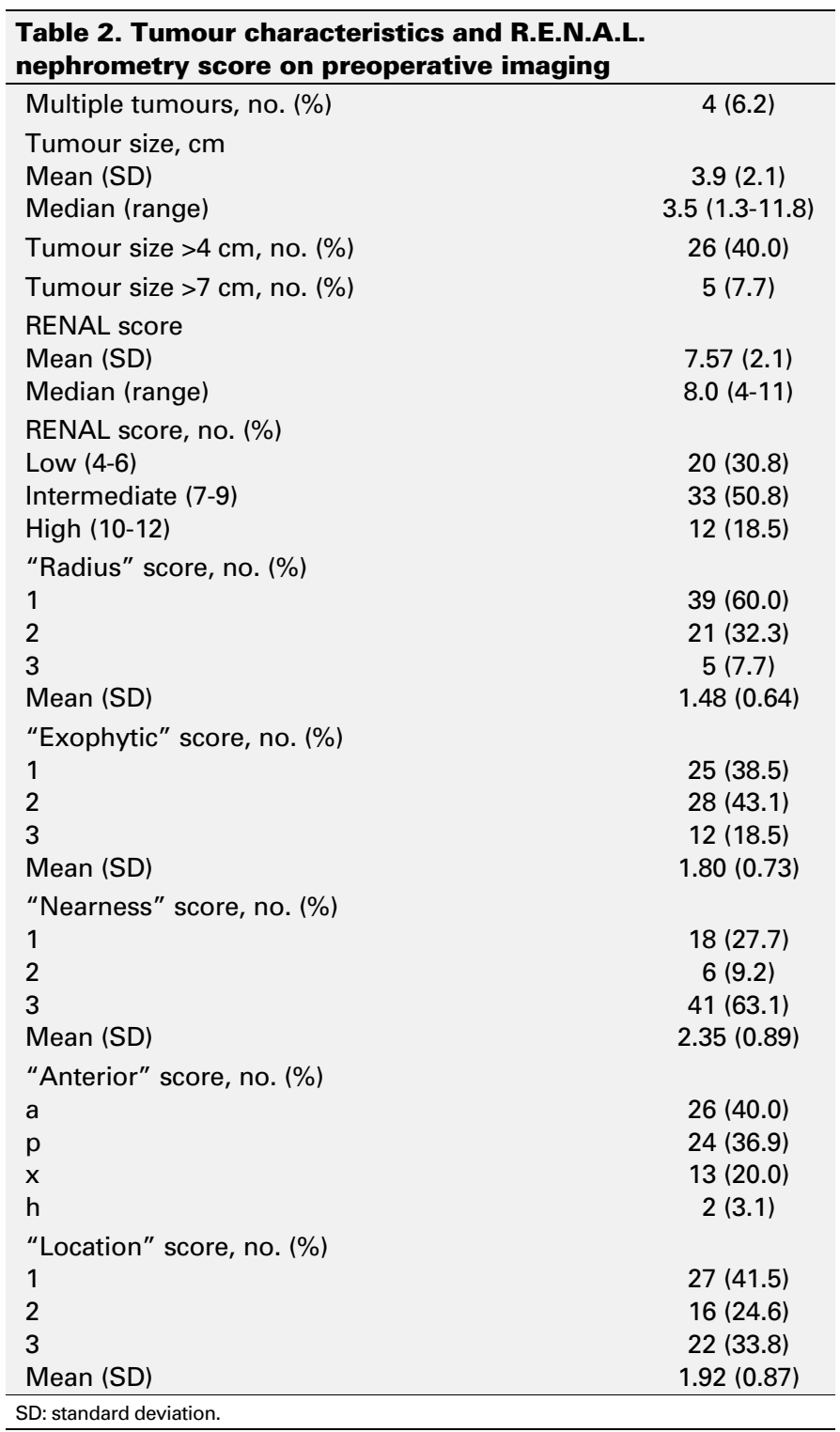

\section{Pathology}

Pathologic features are listed in Table 5 . Overall, $81.4 \%$ of tumours were malignant. Clear cell renal carcinoma was the most predominant type ( $43.1 \%$ of all tumours). Benign tumours included angiomyolipomas $(7.7 \%)$, oncocytomas $(4.6 \%)$ and adenomas (6.2\%). High-grade disease was reported in $20 \%$ of cases. A pT3a disease was seen in $28.1 \%$ and positive surgical margins were noted in $7.7 \%$ of cases.

\section{WIT and learning curve}

Factors associated with WIT are shown in Table 6. First, we assessed the linear correlation between WIT and quantita- 


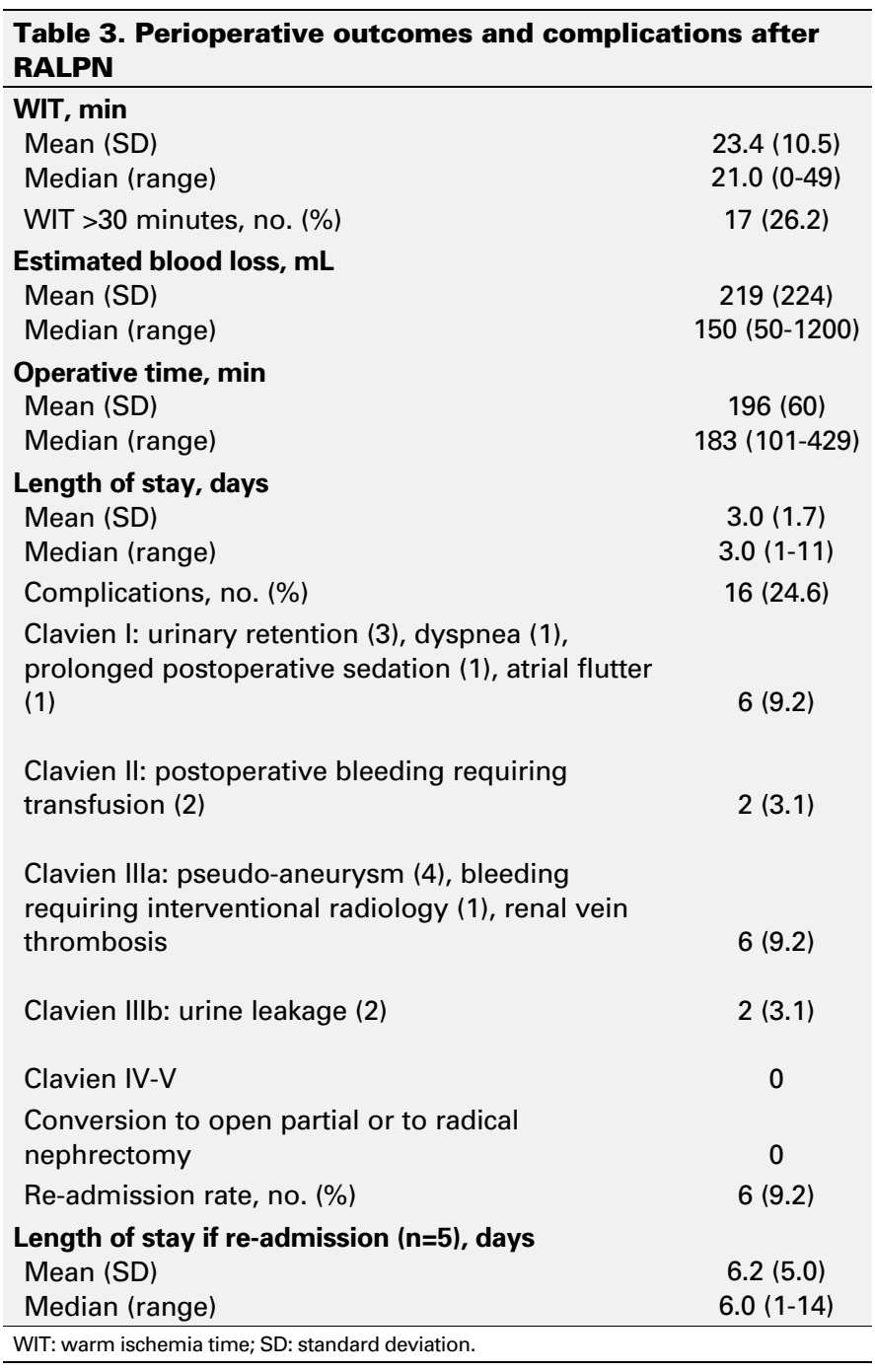

tive parameters using Pearson's coefficient. Tumour size, R.E.N.A.L. score and change in creatinin were linearly correlated with WIT in linear regression analysis. BMI was not linearly correlated with WIT.

Second, we used the 20-minute cut-off to assess qualitative parameter associations in univariable analysis. When studying postoperative parameters (hospital stay, complications, re-admission rate), the reference was a WIT $<20$ minutes to assess whether a WIT $>20$ minutes would affect these outcome parameters.

When using the WIT cut-off of 20 minutes, R.E.N.A.L. nephrometry score and tumour size remained statistically significant for WIT prediction. Surgeon experience and the complication rate were also significantly correlated with WIT. The mean WIT was 16.6, 24.9 and 30.7 minutes when the R.E.N.A.L. nephrometry score was 4-6, 7-9 and $10-12$, respectively $(p<0.001)$. The risk of WIT $>20$ minutes was increased by 4 -fold $(p=0.021)$ and 8 -fold $(p=0.012)$ in cases of moderately and highly complex renal masses,

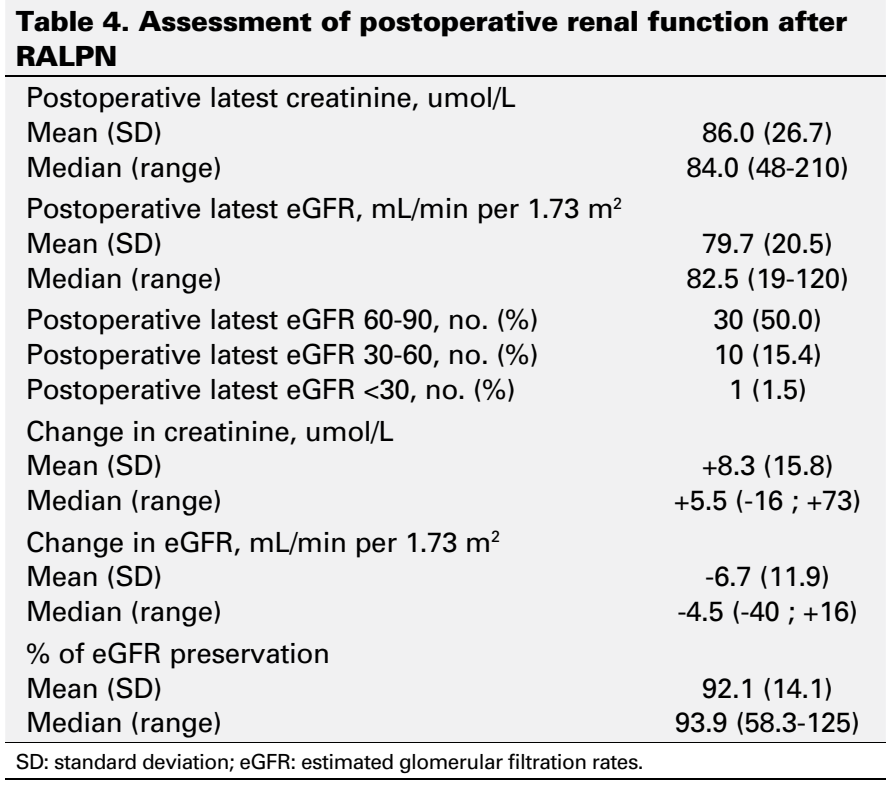

respectively. The mean WIT was shortened by 5 minutes after 20 cases $(p=0.016)$.

We ran a multivariate logistic regression analysis taking into account age, R.E.N.A.L. score and surgeon experience; this confirmed the independent predictive value of R.E.N.A.L. score and surgeon experience for WIT. When a low RENAL score (4-6) was used as reference, a score of 7-9 and of 10-12 increased the risk of WIT $>20$ minutes by 3.3fold and 8.1 -fold (95\% confidence interval [CI]: 1.29-50.4; $p=0.025)$, respectively. When the first 20-case cohort of each surgeon was used as reference, the experience beyond these 20 initial cases positively affected WIT (OR [odds ratio $0.184 ; 95 \% \mathrm{Cl}: 0.05-0.63 ; p=0.007$ ).

The trifecta rate was achieved in $56.9 \%$ of cases. These rates were improved by surgeon experience, likely in R.E.N.A.L. score $7-12$ tumours, to reach $64.3 \%$ after the first 20 cases regardless of the definition (Table 7). As surgeon experience and R.E.N.A.L. score were both predictive of WIT, we decided to stratify experience analysis by R.E.N.A.L. score to identify potentially different changing parameters according to tumour complexity. Concerning the initial experience, the 20 first cases of each surgeon (40 cases) were included. The three operative parameters (WIT, operative time and blood loss) were significantly improved after the 20 initial cases. There was also no significant trend towards lower complications and positive margin rates after the 20 first cases for each surgeon. In R.E.N.A.L. nephrometry scores of $>6$ in renal tumours, the impact of surgeon experience mostly affected operative time rather than blood loss in cases where the renal tumour is not complex (low R.E.N.A.L. nephrometry score). 


\begin{tabular}{lc}
\hline \multicolumn{2}{l}{ Table 5. Pathologic features of removed tumours } \\
\hline Malignant tumours, no. (\%) & $53(81.4)$ \\
RCC, clear cell & $28(43.1)$ \\
RCC, papillary & $14(21.5)$ \\
RCC, chromophobe & $9(13.8)$ \\
RCC, mixed & $1(1.5)$ \\
MEST & $1(1.5)$ \\
Benign tumours, no. (\%) & $12(18.6)$ \\
Angiomyolipoma & $5(7.7)$ \\
Oncocytoma & $3(4.6)$ \\
Adenoma & $4(6.2)$ \\
Positive margins, no. (\%) & $5(7.7)$ \\
Fuhrman grade ( $\mathrm{n}=43$ ), no. (\%) & \\
1-2 & $30(46.1)$ \\
3 & $12(18.5)$ \\
4 & $1(1.5)$ \\
pTNM stage ( $\mathrm{n}=53$ ), no. (\%) & \\
pT1a & $32(60.4)$ \\
pT1b & $10(31.3)$ \\
pT2a & $2(6.3)$ \\
pT3a & $9(28.1)$ \\
\hline RCC: renal cell carcinoma; MEST: mixed epithelial and stromal tumour. & \\
\hline
\end{tabular}

\section{Discussion}

Robotic assistance provides improved dexterity, increased visualization, tremor filtration and surgeon comfort. These advantages have been highlighted in technically demanding procedures, such as laparoscopic partial nephrectomy. Thus, indications of RALPN have been expanded over the last few years and some centres are able to report considerable experience. ${ }^{7,12}$ Nevertheless, to the best of our knowledge, no Canadian robotic experience has yet been published. The aim of this study was to report the surgical outcomes from an initial single-institution experience of RALPN.

Overall, our results in terms of operative time and estimated blood loss were strictly in line with published values. ${ }^{7}$ Length of stay and change in eGFR were also comparable to those published by experienced teams. ${ }^{7}$ The median WIT was slightly longer than that reported by Kaouk and colleagues ${ }^{7}$ (21 vs. 19 minutes), but in line with other reported values. ${ }^{15,18}$

It is important to stratify analyses of perioperative outcomes by the R.E.N.A.L. nephrometry score. This score helps

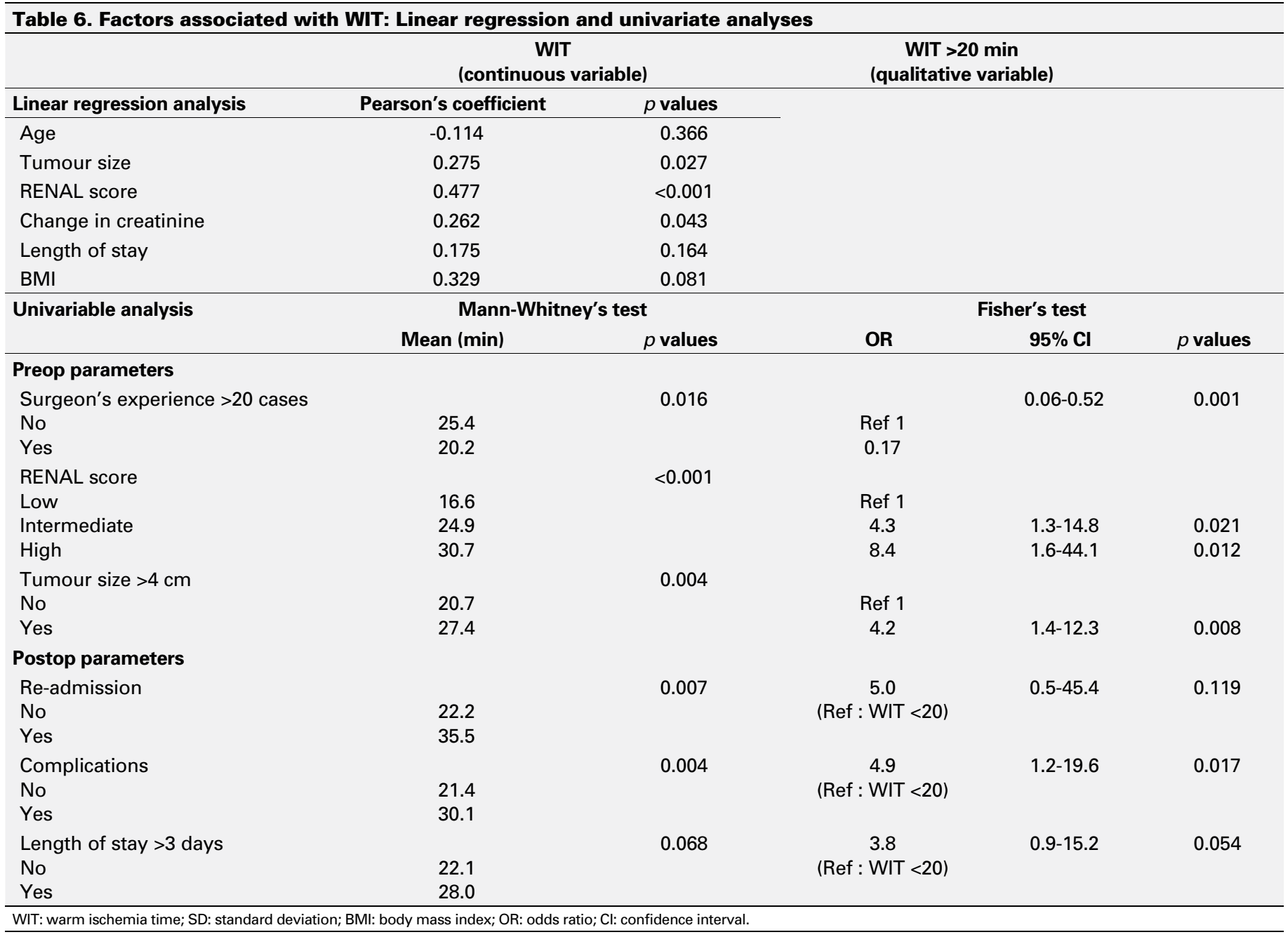




\begin{tabular}{|c|c|c|c|}
\hline & $\begin{array}{l}\text { Initial first } \\
20 \text { cases } \\
\text { experience }\end{array}$ & $\begin{array}{c}\text { Further } \\
\text { cases }\end{array}$ & $p$ values \\
\hline \multicolumn{4}{|l|}{ Overall cohort $(n=65)$} \\
\hline WIT, min & 25.4 & 20.2 & 0.016 \\
\hline Estimated blood loss, mL & 249 & 173 & 0.004 \\
\hline Operative time, $\min$ & 211 & 171 & 0.011 \\
\hline Complications, \% & 32.5 & 12.0 & 0.062 \\
\hline Positive surgical margins, \% & 10.0 & 4.0 & 0.377 \\
\hline \multicolumn{4}{|l|}{ RENAL score $>6(n=45)$} \\
\hline WIT, min & 28.2 & 22.6 & 0.068 \\
\hline Estimated blood loss, mL & 271 & 236 & 0.114 \\
\hline Operative time, $\min$ & 224 & 172 & 0.013 \\
\hline Complications, \% & 33.3 & 14.3 & 0.207 \\
\hline \multicolumn{4}{|l|}{ RENAL score 4-6 $(n=20)$} \\
\hline WIT, min & 15.8 & 17.2 & 0.818 \\
\hline Estimated blood loss, mL & 172 & 94 & 0.016 \\
\hline Operative time, $\min$ & 170 & 170 & 0.820 \\
\hline Complications, \% & 32.3 & 9.1 & 0.178 \\
\hline
\end{tabular}

to characterize tumour anatomy and complexity in a reproducible and quantifiable manner. The role of the R.E.N.A.L. score in the preoperative assessment of RALPN has previously been highlighted. ${ }^{15,19,20}$ As expected, this score was significantly correlated with the WIT, operative time, estimated blood loss and complication rate. ${ }^{21}$ Surgery for a deep endophytic hilar mass will be more technically challenging than that for an exophytic lower pole T1a tumour. Our study population included a significant proportion of moderately to highly complex tumours $(69.4 \%)$ and of tumour $>7 \mathrm{~cm}$ $(7.7 \%)$. This concern may explain our grade 3 complication rate $(12.3 \%)$. The largest single-institution series published by Kaouk and colleagues reported an overall complication rate of $15.3 \%$ versus $24.6 \%$ in our series. ${ }^{7}$ Nevertheless, the median R.E.N.A.L. nephrometry score was not comparable (7 vs. 8 in our series). The complication rate reported by Png and colleagues ${ }^{15}$ was in line with that reported by the Cleveland clinic cohort (13.2\%); however only $47 \%$ of tumours were moderately to highly complex. ${ }^{15}$ In the series of Pierorazio and colleagues only $35 \%$ of tumours were classified as moderately or highly complex..$^{22}$ In a large multicenter series of 886 patients, Tanagho and colleagues reported a complication rate of $23 \%$ in complex tumours. ${ }^{20}$ The learning curve of the technique needs to be emphasized. Our overall complication rate was only $12 \%$ after the 20 initial cases for each surgeon, in line with published values. No grade 4-5 complication rates were reported.

As previously described, we also found that surgeon experience was an independent predictor of perioperative outcomes. ${ }^{19}$ Despite the increased complexity of tumours, operative time, estimated blood loss and WIT showed a decrease over time as previously described. ${ }^{23}$ We used the cut-off of 20 cases, as suggested by Mottrie and colleagues. ${ }^{24}$ Other authors have suggested a 25-case experience concerning the WIT. ${ }^{22,25}$ Our findings tended to confirm this short learning curve, with rapid improvement of operative parameters and a trend towards lower complication rates. The literature also suggested that the transition from pure laparoscopic to RALPN may be faster in experienced laparoscopic surgeons. ${ }^{22,26}$ Despite the increasing tumour complexity, the trifecta outcomes of RALPN improved significantly after 20 cases to achieve the rates $(64.3 \%)$ reported by the most experienced RALPN teams. ${ }^{17,27}$

As compared to larger or multi-institutional series, the strength of our series is its homogeneity concerning the surgical steps, especially in terms of type of clamping and of renorraphy. The largest single institution series published by the Cleveland clinic has described their evolving techniques. ${ }^{7,28}$ Their initial experience included interrupted bolstered renorraphy compared with a continuous horizontal mattress stitch in their contemporary experience. Their type of clamping also varied over time, including laparoscopic bulldogs clamps versus a Satinsky clamp, both artery and vein clamping versus only arterial clamping, and unclamping before versus after renal capsula suturing. All these evolving factors may affect perioperative outcomes.

The literature demonstrated that kidney damage occured when the WIT was $>30$ minutes. This damage is only partially reversible and efforts should be made to keep the WIT within 30 minutes..$^{29,30}$ The optimal WIT should be 20 or 25 minutes. Moreover, robot assistance tends to shorten the duration of WIT as compared to pure LPN. The cut-offs of 20 or 25 minutes were used in recent series. ${ }^{27}$

The retrospective design of our study is one of the main limitations. Some patient characteristics and comorbidities, as well as insignificant postoperative complications, may not have been recorded. Moreover, longer follow-up is needed to assess the oncologic mid-term safety of the procedure. Despite the favourable perioperative outcomes of RALPN, few studies focus on survival outcomes. ${ }^{6}$ A larger cohort might also lead to a more accurate analysis of the learning curve on intraoperative parameters and complication rate.

\section{Conclusion}

RALPN is a safe and feasible procedure for experienced robotic surgeons. The standardization of each surgical step provides low specific morbidity, even for moderately or highly complex renal masses. The reported WIT does not compromise kidney function. Operative time, estimated blood loss and the WIT depends on tumour characteristics, mainly determined by the R.E.N.A.L. nephrometry score and 
Ploussard et al.

may be improved by surgeon experience. Longer follow-up is needed to assess the oncologic mid-term safety of the procedure and a larger cohort might lead to a more accurate analysis of the learning curve.

Competing interests: None declared.

Acknowledgement: Dr Guillaume Ploussard is a recipient of a grant from the Association Française d'Urologie (AFU).

This paper has been peer-reviewed.

\section{References}

1. Cooperberg MR, Mallin K, Kane CJ, et al. Treatment trends for stage I renal cell carcinoma. J Urol 2011;186:394-9. http://dx.doi.org/10.1016/i.juro.2011.03.130

2. Ljungberg B, Cowan NC, Hanbury DC, et al; European Association of Urology Guideline Group. EAU guidelines on renal cell carcinoma: the 2010 update. Eur Urol 2010;58:398-406. http://dx.doi. org/10.1016/i.eururo.2010.06.032

3. Huang WC, Levey AS, Serio AM, et al. Chronic kidney disease after nephrectomy in patients with renal cortical tumours: a retrospective cohort study. Lancet Oncol 2006;7:735-40. http://dx.doi.org/10.1016/ S1470-2045(06)70803-8

4. Fergany AF, Hafez KS, Novick AC. Long-term results of nephron sparing surgery for localized renal cell carcinoma: 10-year followup. J Urol 2000;163:442-5. http://dx.doi.org/10.1016/500225347(05)67896-2

5. Lane BR, Campbell SC, Gill IS. 10-Year Oncological Outcomes After Laparoscopic and Open Partia Nephrectomy. J Urol $2013 ; 190$ :44-9. http://dx.doi.org/10.1016/i.juro.2012.12.102. Epub 2013 Jan 8.

6. Kyllo RL, Tanagho YS, Kaouk JH, et al. Prospective multi-center study of oncologic outcomes of robotassisted partial nephrectomy for pT1 renal cell carcinoma. BMC Urol 2012;12:11. http://dx.doi. org/10.1186/1471-2490-12-11

7. Kaouk JH, Khalifeh A, Hillyer $S$, et al. Robot-assisted laparoscopic partial nephrectomy: step-by-step contemporary technique and surgical outcomes at a single high-volume institution. Eur Urol 2012;62:55361. http://dx.doi.org/10.1016/i.eururo.2012.05.021

8. Mullins JK, Feng T, Pierorazio PM, et al. Comparative analysis of minimally invasive partial nephrectomy techniques in the treatment of localized renal tumors. Urology 2012;80:316-21. http://dx.doi. org/10.1016/i.urology.2012.03.043

9. Long JA, Yakoubi R, Lee $B$, et al. Robotic versus laparoscopic partial nephrectomy for complex tumors: comparison of perioperative outcomes. Eur Urol 2012;61:1257-62. http://dx.doi.org/10.1016/i. eururo.2012.03.012

10. Hillyer SP, Autorino R, Laydner $\mathrm{H}$, et al. Robotic versus laparoscopic partial nephrectomy for bilateral synchronous kidney tumors: single-institution comparative analysis. Urology 2011;78:808-12. http:// dx.doi.org/10.1016/j.urology.2011.06.012

11. Aboumarzouk OM, Stein RJ, Eyraud R, et al. Robotic versus laparoscopic partial nephrectomy: a systematic review and meta-analysis. Eur Urol 2012;62:1023-33. http://dx.doi.org/10.1016/i eururo.2012.06.038

12. Patel HD, Mullins JK, Pierorazio PM, et al. Trends in Renal Surgery: Robotic Technology is Associated with Increased Use of Partial Nephrectomy. J Urol 2013;189:1229-35. http://dx.doi.org/10.1016/i juro.2012.10.024
13. White MA, Haber GP, Autorino $R$, et al. Outcomes of robotic partial nephrectomy for renal masses with nephrometry score of $\geq 7$. Urology 201 1;77:809-13. http://dx.doi.org/10.1016/j.urology.2010.12.005

14. Patel $M N$, Krane $L S$, Bhandari $A$, et al. Robotic partial nephrectomy for renal tumors larger than $4 \mathrm{~cm}$. Eur Urol 2010;57:310-6. http://dx.doi.org/10.1016/i.eururo.2009.11.024

15. Png KS, Bahler CD, Milgrom DP, et al. The role of R.e.N.a.L. Nephrometry score in the era of robotassisted partial nephrectomy. J Endourol 2013;27:304-8. http://dx.doi.org/10.1089/end.2012.0182

16. Kurella Tamura $M$, Anand $S$, et al. Comparison of $C K D$ awareness in a screening population using the Modification of Diet in Renal Disease (MDRD) study and CKD Epidemiology Collaboration (CKD-EPI) equations. Am J Kidney Dis 2011:57:17-23. http://dx.doi.org/10.1053/i.ajkd.2010.11.008

17. Hung AJ, Cai J, Simmons MN, et al. «Trifecta» in partial nephrectomy. J Urol 2013;189:36-42. http:// dx.doi.org/10.1016/i.juro.2012.09.042

18. Masson-Lecomte A, Bensalah K, Seringe E, et al. A prospective comparison of surgical and pathological outcomes obtained after robot-assisted or pure laparoscopic partial nephrectomy in moderate to complex renal tumours: results from a French multicentre collaborative study. BJU Int 2013;111:256-63. http:// dx.doi.org/10.1111/j.1464-410X.2012.11528.x

19. Ficarra V, Bhayani $S$, Porter J, et al. Predictors of warm ischemia time and perioperative complications in a multicenter, international series of robot-assisted partial nephrectomy. Eur Urol 2012;61:395-402. http://dx.doi.org/10.1016/j.eururo.2011.10.046

20. Tanagho YS, Kaouk JH, Allaf ME, et al. Perioperative Complications of Robot-assisted Partial Nephrectomy: Analysis of 886 Patients at 5 United States Centers. Urology 2013:81:573-80. http://dx.doi. org/10.1016/i.urology.2012.10.067

21. Petros F, Sukumar $S$, Haber GP, et al. Multi-institutional analysis of robot-assisted partial nephrectomy for renal tumors $>4 \mathrm{~cm}$ versus $\leq 4 \mathrm{~cm}$ in 445 consecutive patients. J Endourol 2012;26:642-6. http:// dx.doi.org/10.1089/end.2011.0340

22. Pierorazio PM, Patel HD, Feng T, et al. Robotic-assisted versus traditional laparoscopic partial nephrectomy: comparison of outcomes and evaluation of learning curve. Urology 2011;78:813-9. http://dx.doi. org/10.1016/i.urology.2011.04.065

23. Yuh B, Muldrew $S$, Menchaca A, et al. Integrating robotic partial nephrectomy to an existing robotic surgery program. Can J Urol 2012;19:6193-200.

24. Mottrie A, De Naeyer $G$, Schatteman $P$, et al. Impact of the learning curve on perioperative outcomes in patients who underwent robotic partial nephrectomy for parenchymal renal tumours. Eur Urol 2010;58:127-32. http://dx.doi.org/10.1016/i.eururo.2010.03.045

25. Haseebuddin M, Benway BM, Cabello JM, et al. Robot-assisted partial nephrectomy: evaluation of learning curve for an experienced renal surgeon. J Endourol 2010;24:57-61. http://dx.doi.org/10.1089/ end.2008.0601

26. Lavery HJ, Small AC, Samadi DB, et al. Transition from laparoscopic to robotic partial nephrectomy: the learning curve for an experienced laparoscopic surgeon. JSLS 2011;15:291-7. http://dx.doi.org/10.4 293/108680811X13071180407357

27. Khalifeh A, Autorino R, Hillyer SP, et al. Comparative outcomes and assessment of trifecta in 500 robotic and laparoscopic partial nephrectomy cases: a single surgeon experience. J Urol 2013;189:1236-42. http://dx.doi.org/10.1016/i.juro.2012.10.021

28. Kaouk JH, Hillyer $S P$, Autorino $R$, et al. 252 robotic partial nephrectomies: evolving renorrhaphy technique and surgical outcomes at a single institution. Urology 2011;78:1338-44. http://dx.doi.org/10.1016/i. urology.2011.08.007

29. Patel AR, Eggener SE. Warm ischemia less than 30 minutes is not necessarily safe during partial nephrectomy: every minute matters. Urol Oncol 2011;29:826-8. http://dx.doi.org/10.1016/j.urolonc.2011.02.015

30. Porpiglia $F$, Renard J, Billia $M$, et al. Is renal warm ischemia over 30 minutes during laparoscopic partial nephrectomy possible? One-year results of a prospective study. Eur Urol 2007;52:1 170-8. http://dx.doi. org/10.1016/i.eururo.2007.04.024

Correspondence: Dr. Guillaume Ploussard, Department of Urology, Jewish General Hospital and Montreal General Hospital, McGill University, Montreal, QC; g.ploussard@gmail.com 